\title{
A RETA E A CURVA: A ESTÉTICA DA PAISAGEM?*
}

\author{
EULER SANDEVILLE JUNIOR
}

Arquiteto e paisagista, formado em Educação Artistica, mestre, doutourando FAUUSP, especialização em ecologia. Professor da Escola de Engenharia de São Carlos, USP, Universidade São Judas Tadeu, Universidade Bráz Cubas e Universidade Católica de Santos. 


\title{
RESUMO
}

á uma idéia comum de que o "paisagismo formal" seja uma expressão autoritária do domínio humano sobre a natureza e de que o "paisagismo informal" expresse identificação com a natureza. Este texto procura evidenciar o campo simbólico por trás desses estereótipos recorrentes na história e teoria do projeto paisagístico.

Polarizações semelhantes também ocorrem no campo da edificação e do urbanismo, mostrando que a tensão entre o formal e o informal, ou o racional e o orgânico, ou a reta e a curva como a designamos aqui, se torna veículo de conteúdos que transcendem em muito o campo estrito do desenho.

A compreensão desse campo simbólico é necessária para uma justa apreciação das obras-primas do passado e para a investigação da relação histórica entre projeto, natureza e cultura, tema tão pertinente ao paisagismo.

\begin{abstract}
T

here are a common compreension in landscape architecture that formal design is like a hard human dominance over nature and the organic or informal landscape means total identification with nature.

Then I think that the understanding of the simbolism in landscape architecture is basic to our compreension of the pastmasterpiece and tothe compreension of the historic relationship between nature, culture and design that is the base to studies about landscape architecture.

The kind of contrasts like straight line against curve lines, the rational aganist the organic, are also very common in architecture and urban design and my intention in this paper is to introduce my thinking about these.

"Na ilusão o desejo basta a si mesmo; não espera nenhum apoio da experiência" (Rosset, 1989)

"Parks and gardens of curves are always new, always revealing new thoughts and new interests in life. Straight lines are copied from the achitect and do not belong to the landscape. They have nothing to do with nature, of which landscaping is a part and out of which art has grown. Landscaping must follow the lines of the tree with its thousands of curves.
\end{abstract}

(Jensen, 1956') 


\section{NO PAISAGISMO}

Este texto discute a idéia de que os estilos formal e informal do projeto dos jardins sejam, em si, uma relação de identificação ou estranhamento com a natureza, tal como proposto por autores importantes para a formulação do que hoje entendemos como paisagismo (Quadro 1). Cidade e campo são, talvez, os conceitos subjacentes que melhor expressem o imaginário contido nessa tensão entre a reta e a curva e entre despotismo e democracia, implícitos também nessa discussão, como veremos.

\begin{tabular}{|l|l|}
\hline \begin{tabular}{l|l|}
\hline QUADRO 1 \\
AUTOR
\end{tabular} & CONCEıTos \\
\hline Hubbard, 1927 & humanizado e naturalista \\
\hline Eckbo, 19502 & $\begin{array}{l}\text { formal e informal, clássico e romântico, geométrico e } \\
\text { biologico, arquitetura e natureza, cidade e campo }\end{array}$ \\
\hline Church, 1955 & $\begin{array}{l}\text { formal e informal, simétrico e pitoresco, geométrico e } \\
\text { natural, clássico e romântico }\end{array}$ \\
\hline Jonhson 3 & $\begin{array}{l}\text { formal e informal, retilíneo e sinuoso, arquitetônico e } \\
\text { naturalista }\end{array}$ \\
\hline
\end{tabular}

Alega-se que o modelo forma/ corresponderia a uma relação de estranhamento e oposição com a natureza, subordinando-a ao trato utilitário e predatório, o que seria característico da civilização ocidental e, em particular, de seus governos mais autoritários. Não estamos aqui falando só de desenho, portanto ${ }^{4}$. A oposição entre a reta e a curva trata-se, na verdade, de uma visão crítica e ideológica dos valores da civilização européia.

Há nesses jardins formais a idéia, tão presente no classicismo, de uma academia ${ }^{5}$ de jogos físicos, literários e filosóficos. Essa idéia nos parece particularmente forte nos jardins renascentistas italianos, cuja linguagem, como não poderia deixar de ser, fora buscada no passado romano. $O$ ápice desse modelo foi atingido na França barroca, quando a procura magnificente do infinito 
levou à escala gigantesca de Versalhes, expressando o poder absoluto do monarca em inúmeras alegorias cósmicas (zodiacais e geométricas) e mitológicas.

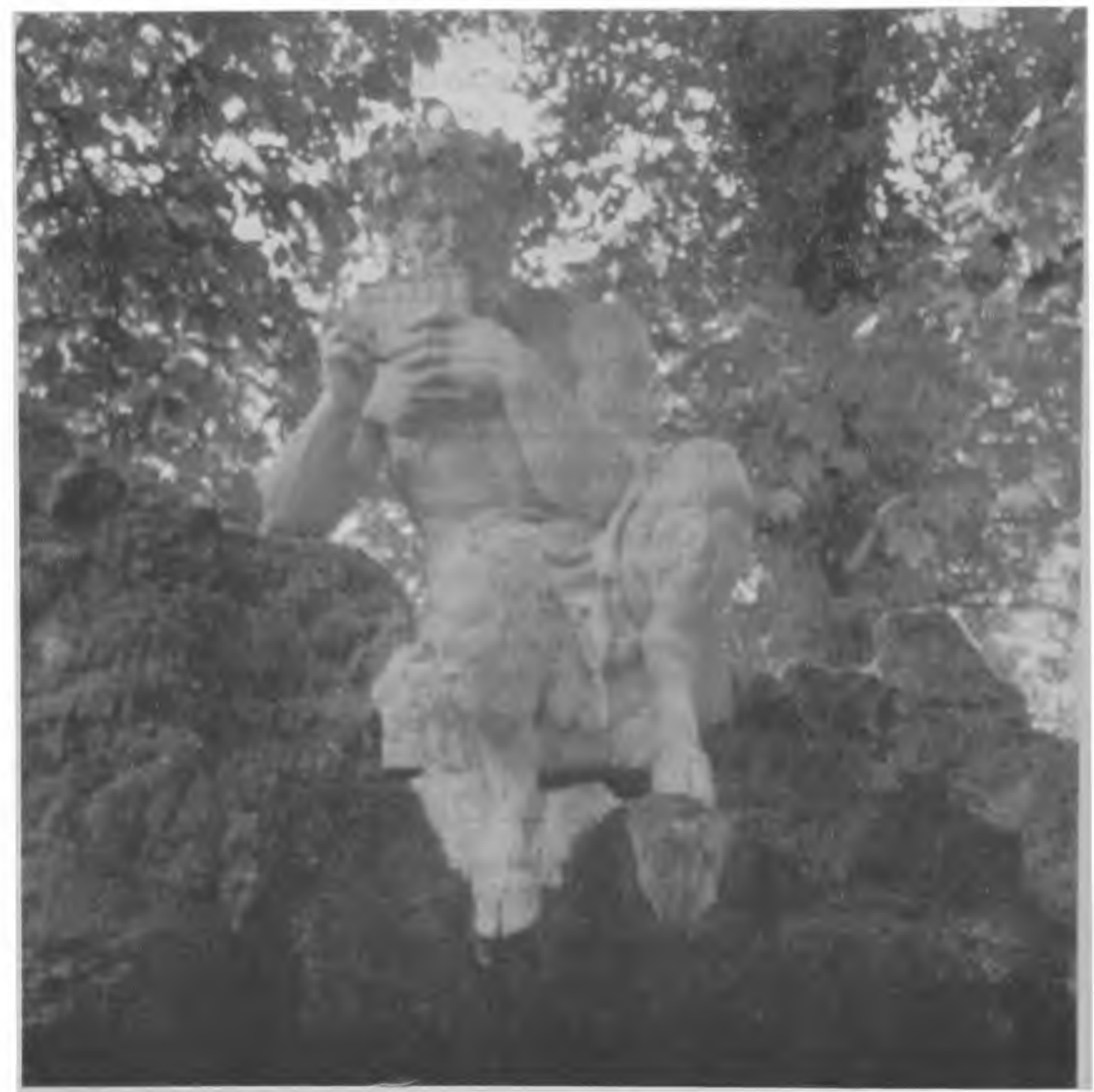

1 - Escultura de Pan, Parque na Alemanha. (In: ENGE, Torslen Olaf; SCHRÖER, Carl Friedrich. Ciarden architecture in Europe, 1450-1800. Benedikt Tasclıen, 1992).

Talvez a rejeição do desenho formal tenha raízes profundas. Rejeita-se com ele a forma arcaica de governo que representava, despótica, encerrada com o divisor de águas da história contemporânea, a Revolução Francesa. Esta forma de governo foi 
destronada no plano ideológico pelo exame da razão, que supostamente levaria à livre determinação de todos os homens e que preparava as democracias deste século. E é interessante que o parque monumental francês seja rejeitado justamente em nome da visão naturalista do parque inglês, a nação que preparava a mais intensa exclusão do homem do campo e as bases de um sistema econômico fundado em intensas comunicações territoriais com referência nos grandes centros urbanos e na indústria.

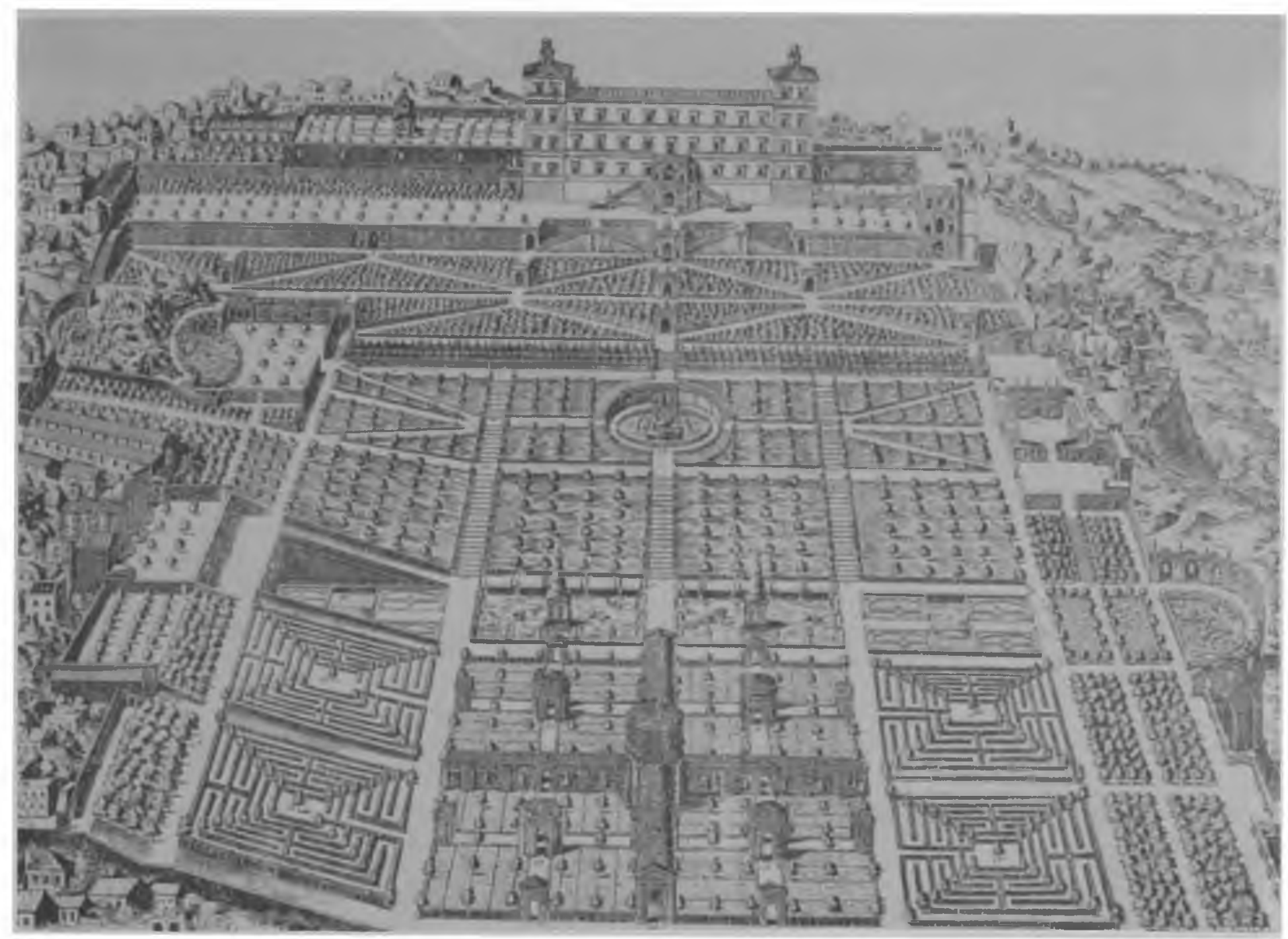

2 - Villa d'Este, Itália, séc. XVI. Gravura de Dupérac. (In: ENGE \& SCHRÖER, op. cit. p. 43). 
O modelo informal seria tributário da visão oriental do jardim, de identificação silenciosa com os símbolos do cosmo ou simplesmente com o prazer contemplativo de uma cena que, em sua construção, passou a reter uma imagem de natureza. $O$ jardim oriental constrói um caráter imitativo sagrado, um lugar de intimidade reflexiva, devendo sempre despertar um estado espiritual mais que hedonista. Trata-se de uma natureza idealizada e abstrata, ritualizada, poética, mística, codificada ${ }^{6}$, e portanto, de grande apelo. Sua apropriação na Inglaterra revolucionou a forma de ver a natureza no ocidente no século 18. Revolução que, obviamente, não era das formas apenas, mas do pensamento e da política, aos quais se ofereceu um vocabulário espacial adequado.

DAlTERES AXighls.
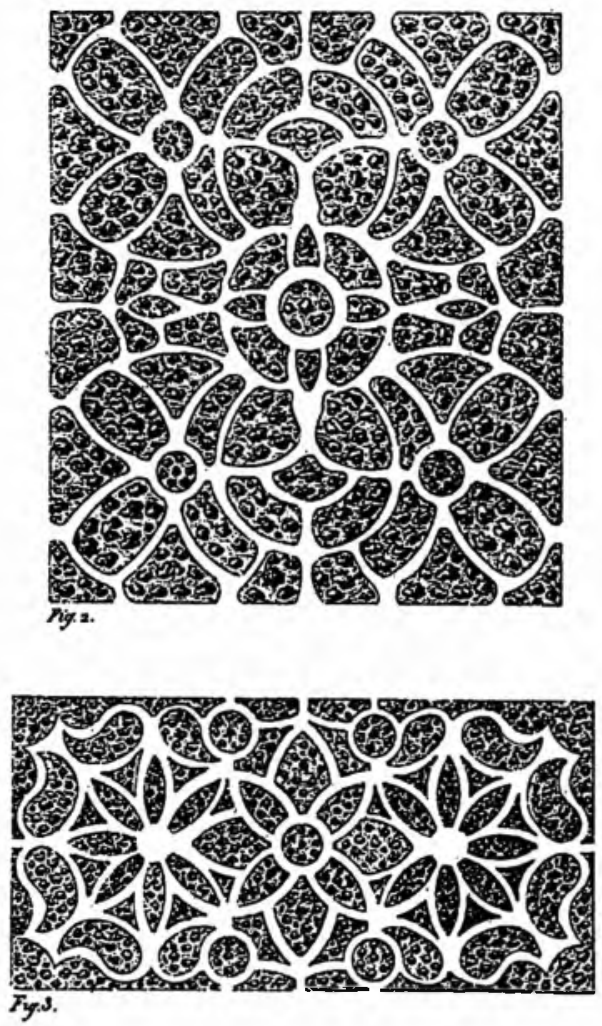

IARDIN MLTET.

P2. $3 \mathrm{kr}$.

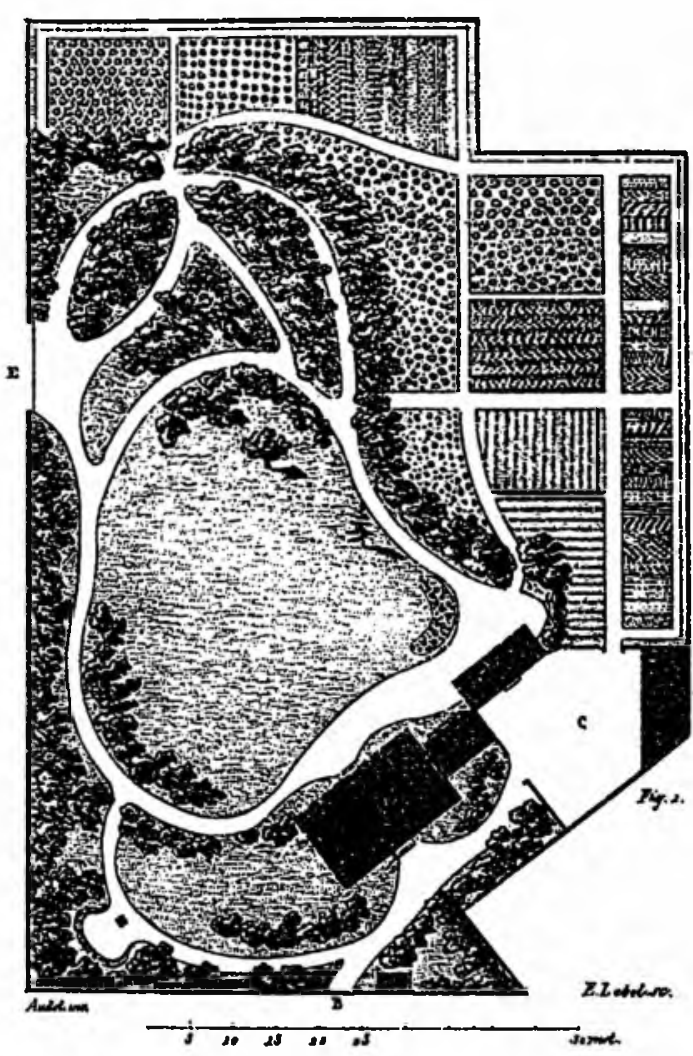

6 - "Jardin mixte" e"Parteres Aglais" (In:AUDOT, L.E. Trate de la composition et de l'ornament des jardins. Paris, Inter-livres, fac-símile, p. 3). 
Essas visões da natureza, em que pesem suas influências orientais, são tributárias de valores bastante ocidentais, como o demonstra sua dívida ao mito da Arcádia em Claude Lorraine, a sua origem literária, e o desenvolvimento das ciências naturais nas pisadas da expansão e transformação colonialista. Talvez a essência do jardim ocidental naturalista seja o parecer com a natureza. É assim que o modo informal/oriental preenche com um caráter animista e interativo o conceito de natureza, aparentemente com uma ótica não antropocêntrica (apesar de serem um capricho de landlords ingleses). É por isso facilmente identificável como mais ecológico, categoria subjacente ao debate que aliás é inaceitável, pois a noção de ecologia é posterior aos fatos em questão, embora, com certeza, seja devedora dos valores culturais e modo de ver o mundo, que se formam nos séculos 17 e 18 .

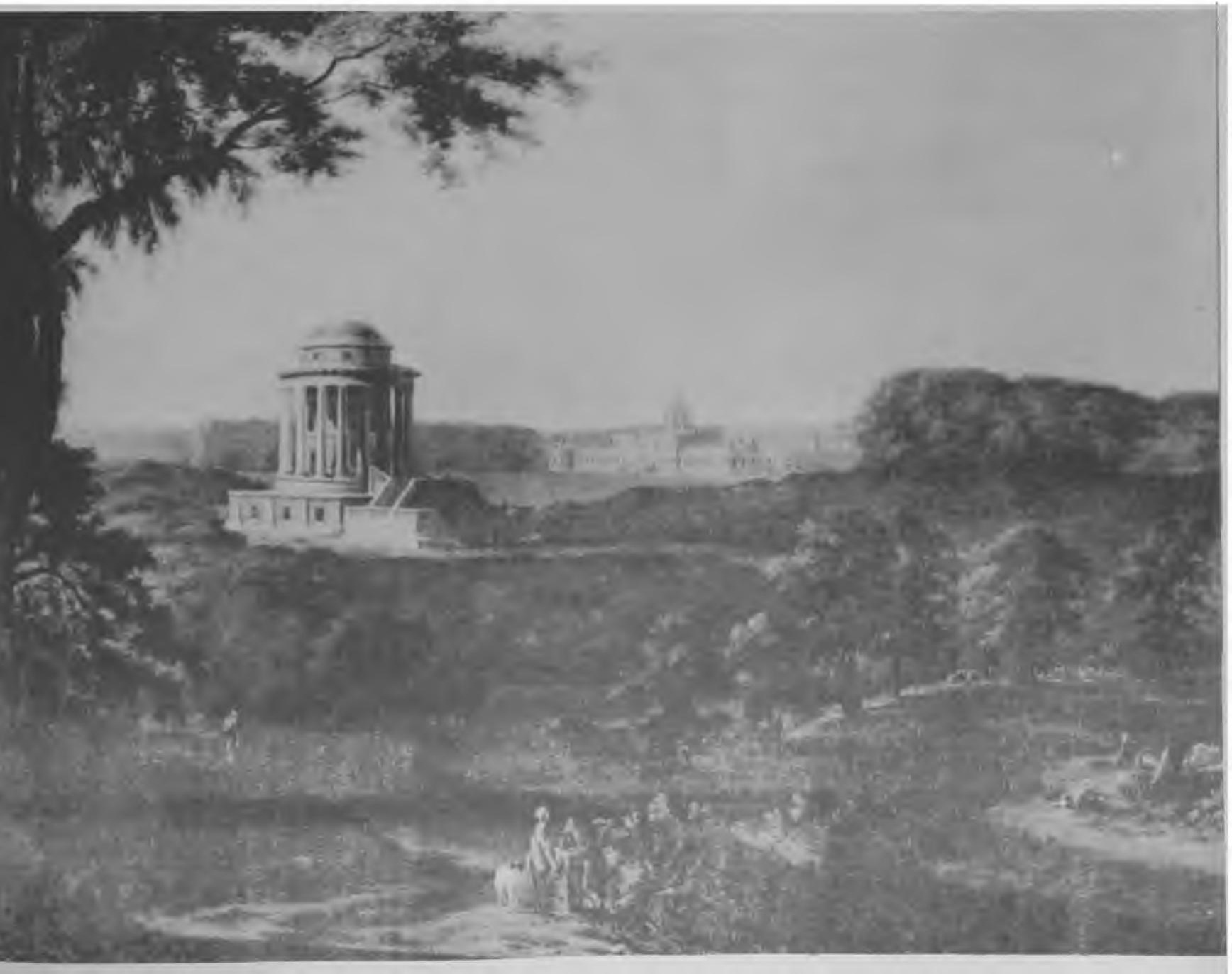


Nada nos permite supor que um seja ecológico e outro não, ou antes, que não sejam ambos fatura humana, subordinando a natureza aos seus desejos de representação e ordenação, modos diferentes de apropriação e posse, que o século 19 retiraria do domínio exclusivo dos nobres, colocando-os à apreciação da multidão dos centros urbanos, quando uns e outros se tornaram parques públicos. Com o séçulo 19, a urbanização, a industrialização e os sistemas de transportes regionais colocaram em crise a relação campo-cidade. A natureza surge então como um símbolo muito forte de uma qualidade de vida perdida. Esse retorno romântico à natureza e ao passado era impossível, mas demonstrava muita vitalidade e criatividade.

8 - Parc des Buttes-Chaumont, c. 1863(/n:JELL/COE, Geoffrey and Susan, op. cit. p. 257).

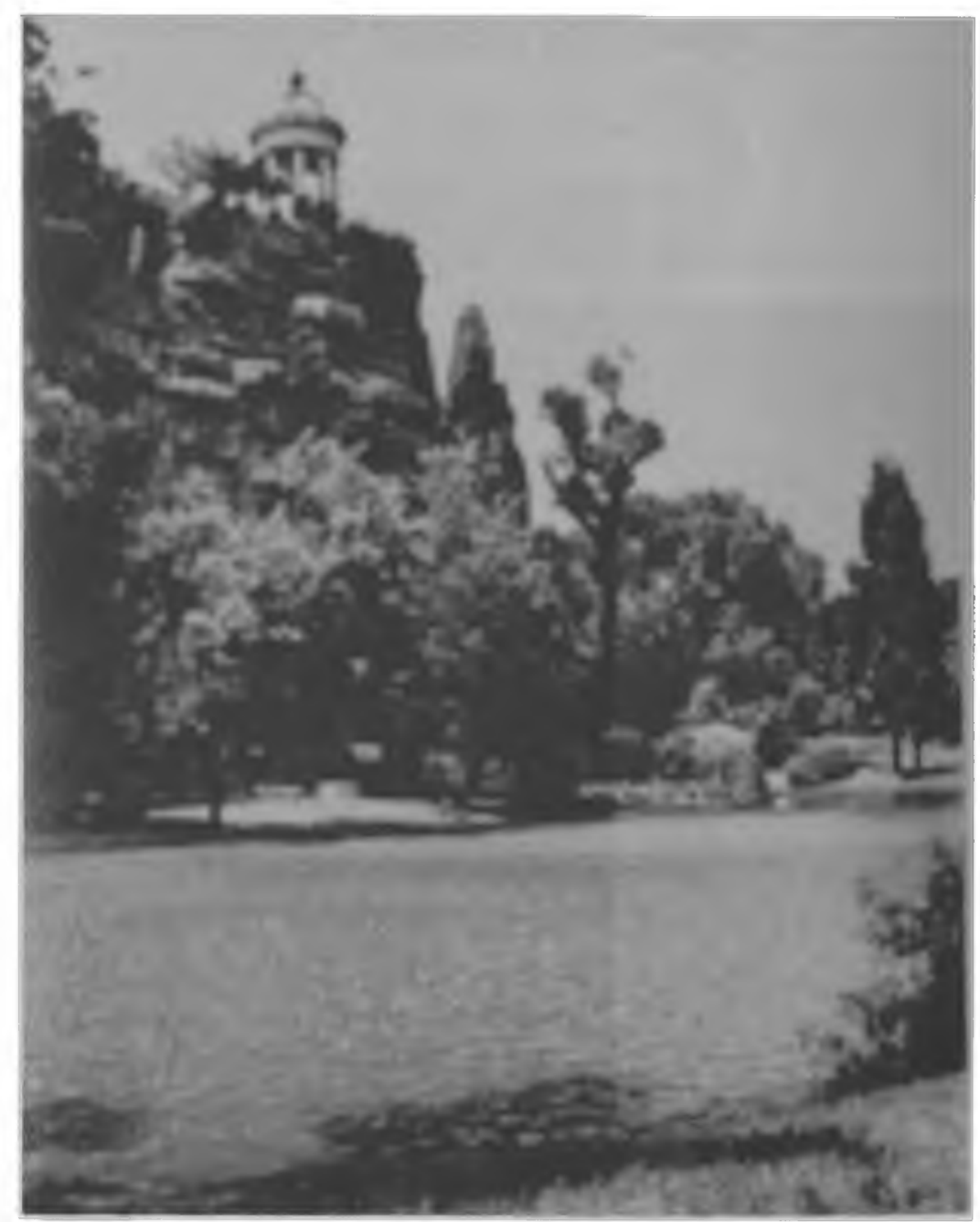




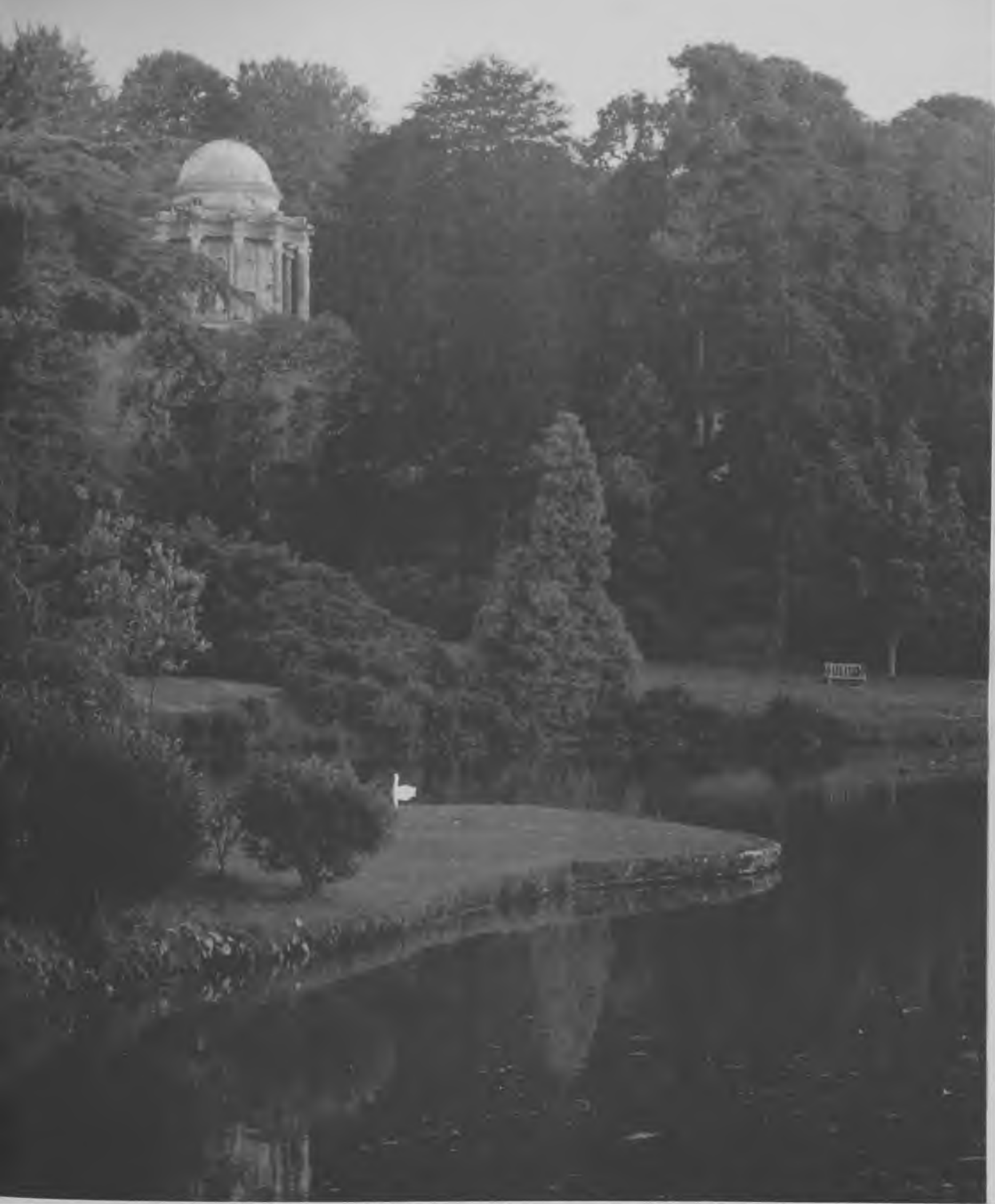

9 - Vista do Templo de Apolo, Stourhead, sec XVIII (In: ENGE \& SCHROER, op. cit. p. 217).

Paisagem Ambiente Ensaios São Paulo n. 8 p. 147 - 173 dez. 1995 
A polarização campo-cidade, como expressou Eckbo em 19507, evidencia o preconceito subjacente a formal e informal a partir do século 18, istoé, da Revolução Industrial, quando a discussão do jardim no âmbito do campo passará a ser uma discussão do jardim (ou natureza) perdido pela cidade. A memória do campo (idealizado) é inserida simbolicamente na cidade do século 19 , mas deixa de ser a Arcádia para ser o lazer e a respiração do aglomerado urbano. De qualquer modo, esses preconceitos naturalistas passaram para os desenhos dos parques urbanos das cidades industriais ${ }^{8}$. Alphand, depois Olmsted e outros, trariam a "natureza" para a cidade, qualificando o ambiente urbano. Os parques do passado dão a linguagem do desenho, mas o paisagismo tornou-se uma questão urbana, ligado definitivamente à forma e qualidade de vida nas grandes cidades.

Os traçados dos parques de Alphand se contrapunham como lugar da natureza ao traçado geométrico do urbanismo barroco adotado por Haussmann e cuidadosamente edificado. Esse conceito de parque chegou também ao Rio de Janeiro e a São Paulo, redesenhou nossos parques e deu a linguagem dos novos até a atualidade. Mas não se deve pensar que o desenho formal foi banido desde o século 18 até o presente, pois no ecletismo deu a linguagem de muitos jardins. Mesmo o planejamento das cidades, sob a influência do art déco, propôs espaços livres públicos segundo essa concepção, que se atualizava com a modernidade elegante de Paris e com a modernidade eficiente das cidades norte-americanas ${ }^{9}$.

O movimento moderno buscava a negação das regras do desenho acadêmico do ecletismo e a amenização, através da inclusão de elementos naturais, do entorno das edificações e do espaço urbanizado. Entre as regras rejeitadas (mas não de todo) pelo modernismo, estão a simetria, a subdivisão em partes autônomas a serem recompostas num todo, perspectivas e eixos de composição, a rígida hierarquia das partes, ornatos, etc., que também estruturavam a linguagem dos jardins formais.

A polêmica persiste até data bastante recente como fulcro do projeto paisagístico, mesmo quando já se começava a advogar 
uma outra postura frente ao design, segundo Eckbo: "Estes dois elementos contrastantes da tradição do paisagismo mundial - a geometria ocidental e a irregularidade oriental, autoridade do homem sobre a natureza e respeito pela natureza, a linha reta $e$ a curva livre - estão ainda no século 20 nos comers da teoria oficial do projeto paisagístico como é ensinado nas Faculdades da América"10.

É interessante que o pós-modemo torna a apropriar-se desse tipo de referência para ambientar suas edificações. $O$ historicismo recente reabilita o desenho e o sentimento do jardim formal eclético (IBA, Boffill, Graves), os quais, entretanto, não são um desenho clássico e, sim, mais uma das notas dissonantes de caráter surrealista em que se embaralham as hipóteses das décadas de 70 e 80 . De qualquer modo, têm o mérito de reeditar a questão dos conteúdos veiculados pelo desenho, ainda que muitas vezes, infelizmente, de maneira estereotipada.

\section{NA ARQUITETURA E NO URBANISMO}

A polêmica não foi exclusiva ao paisagismo. A arquitetura e especialmente o urbanismo moderno, em sua origem, revelam essa disputa ideológica entre a reta e a curva ${ }^{11}$. Os pates $d^{\prime}$ oise e rond points de Versalhes estão tipologicamente no traçado de todas as nossas cidades, tanto quanto o sinuoso traçado dos bairros-jardins. Qualquer análise dos tantos exemplos teóricos e projetuais que possamos escolher para discutir o campo na cidade, como imaginário onde se encontram as tradições agrárias do jardim e as urbanas do chão, da ágora, mostrará que mais do que pares de opostos, cada projeto (cada protótipo) procurou definir qualidades espaciais ricas em relações e significados.

A reta e a curva dos parques franceses e ingleses se reencontram na formulação do urbanismo moderno, traduzidas em polêmicas entre seus expoentes. Vemos que a forma, tão essencial ao paisagismo, também o é para o urbanismo desde sua origem. Do mesmo modo que no paisagismo, no urbanismo a reta e a curva significaram algo mais do que apenas uma opção formal. 


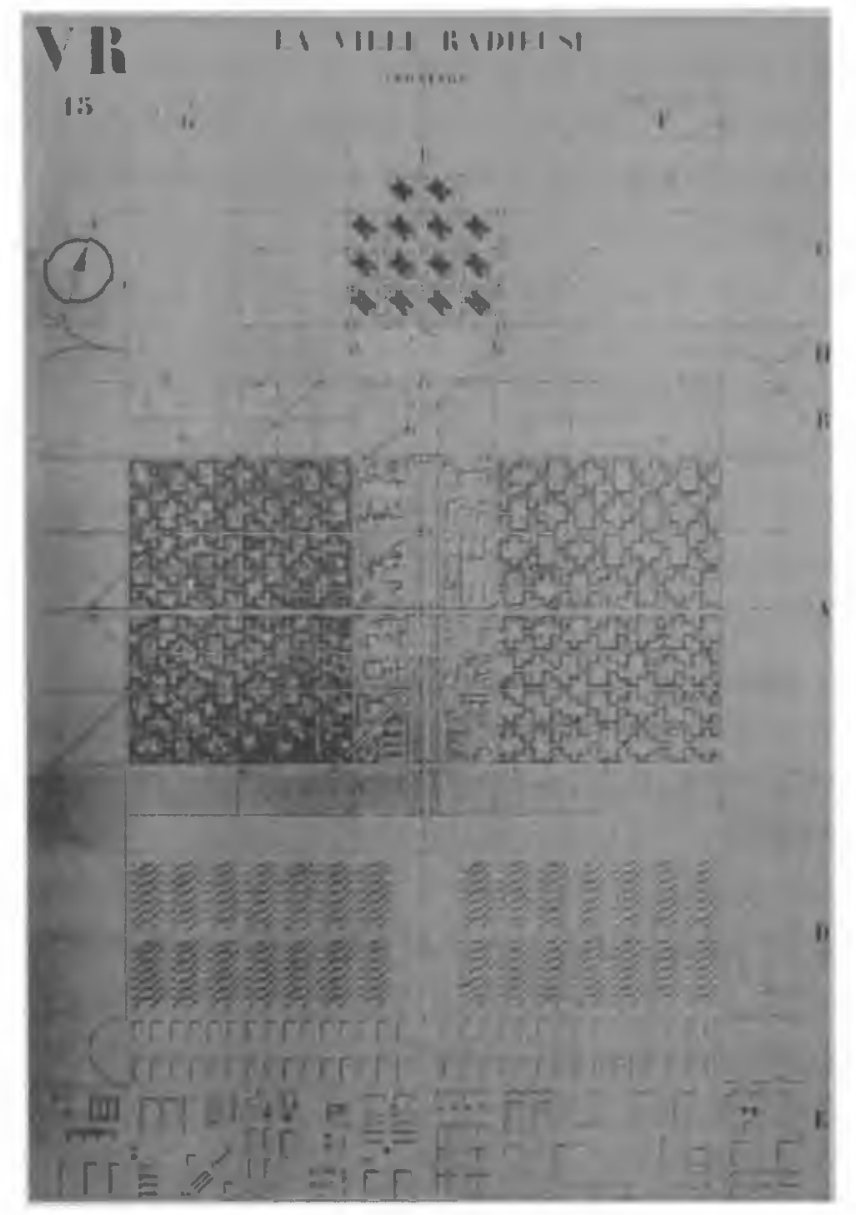

10 Ville Radieuse, Le Corbusier, 1935 (In: JELLICOE, Geoffrey and Susan, op. cit. p. 295).

Uma das constantes no pensamento sobre arte, arquitetura e urbanismo, são os argumentos sobre os aspectos formativos da personalidade que exercem as qualidades formais, constituindo, por vezes, extensas e acirradas polêmicas, invocando analogias com a natureza e com a objetividade científica para autorizarem-se: "A estreiteza da rua, a tortuosidade da rua, o ambiente corrosivo da rua, podem concorrer no homem, desde a infância, para a estreiteza de vistas e até mesmo para a tortuosidade do caráter, cujos resultados maus só a instrução e a educação podem corrigir (...) a influência da linha reta no moral e no físico do homem não é uma ficção; a reta éo caminho por onde a luz se propaga e difunde para chegar aos nossos olhos; é também o caminho por onde a luz chega ao nosso espírito, e a prova é que a linha reta do dever é um fato moral"n?. 
Poderemos rapidamente supor que a relação entre a estreiteza da rua, a estreiteza de visão e a tortuosidade do caráter, é uma proposição antiquada e reacionária do ecletismo, que escamoteia as condições sociais com argumentos positivistas, que nada têm a ver com o mundo moderno. Poderemos supor que sejam pensamentos daquele ecletismo que censurava as fachadas modernas acusando-as de imorais, como Christiano das Neves escreveu sobre a casa no Pacaembu de Warchavchik, em 1930, comparando-a a um prolongamento do cemitério do Araçá ${ }^{13}$.

O que ocorreu, porém, é que o próprio movimento moderno construiu-se posicionando-se nessas polêmicas, advogando a nudez de suas fachadas geométricas como reação ao caráter degenerado e dissimulado, por que não feminino, da ornamentação: "Os engenheiros são viris e saudáveis, úteis e ativos, morais e alegres. Os arquitetos são desencantados e desocupados, faladores ou lúgubres. É que em breve não terão mais nada para fazer", escrevia Le Corbusier em $1923^{14}$ Também Loos, comparando o ornamento com um delito em $1908^{15}$, propunha uma arte da utilidade e da economia. A própria historiografia do movimento modernoo estabelece sobre bases morais ao retornar a Ruskin e Morris como ponto de partida ${ }^{16}$. Não se propunha apenas a eficiência das funções, formas e materiais, mas sua verdade!

As cirurgias urbanas que advogava Le Corbusier nos tecidos tradicionais das cidades, e que elogiava em Haussmann e Pereira Passos, contrapunham o caminho dos asnos, ao qual identificava a difusão das idéias sittescas, ao caminho dos homens, pois afirmava Le Corbusier: "o homem pratica a ordem, seus atos $e$ pensamentos são regidos pela reta e pelo ângulo reto" ${ }^{17}$

Assim, é natural que Le Corbusier expressasse em visita ao Rio de Janeiro, em 1936: "Bem sei que o prodigioso espetáculo natural que envolve e domina o Rio-suas baías, suas montanhas - existiram sempre. Faltava entretanto dar a esses elementos naturais e exuberantes o meio de nos tocar profundamente. Era preciso encontrar a escala humana que pudesse servir de base 
de apliçą̧ã Sem Passos o Rio permaneceria uma agradável cidade de colônia. Gom Passos ... ingressou de vez no rol das grandes capitais, do mundo: Rio paisagem admirạvel, transformoul-se em Rio, grande cidade..."1" . Por trás desta afirmação, devemos reconhecer sua visão de natureza: "A natureza se apresenta antenossos olhos em forma cabtica. O conhecimento racional não nos pộe em contradição com o universo, mas em harmonia, permitindo atuar. Oespírito da matureza é de ordem, como sabemos" 1 .

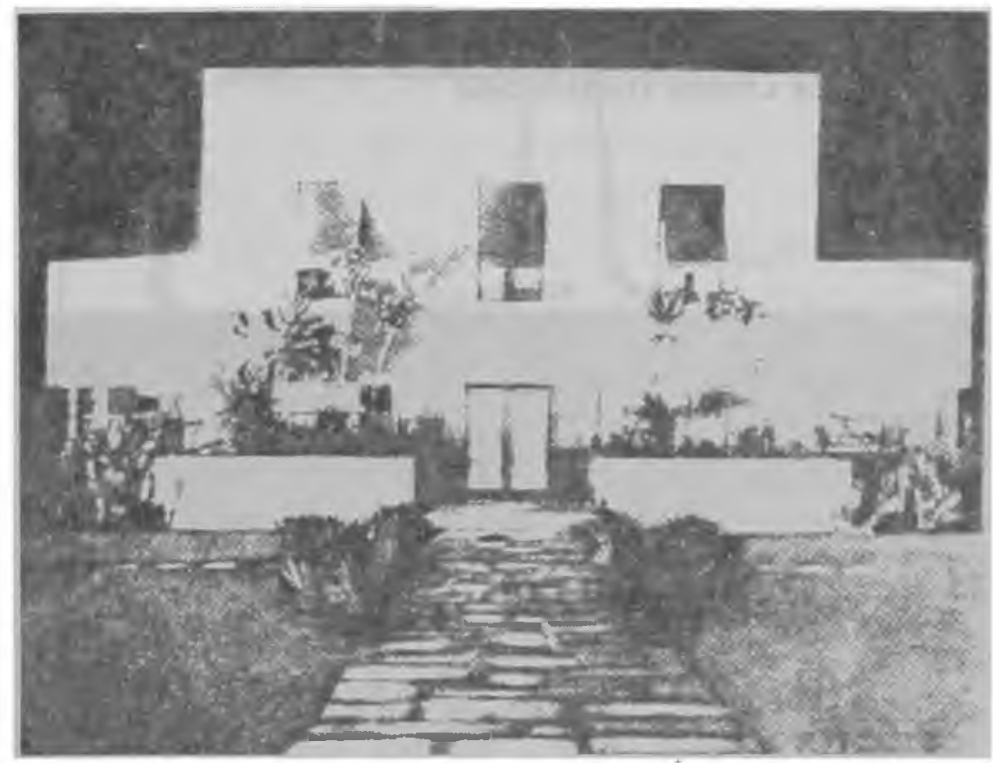

13 - Casa Modernista na rua Santa Cruz, São Paulo, Gregori Warchavchik, 1927. (In: FISCHER, Sylvia e ACAYABA, Marlene Milan p. 9).

Nesses termos, a relação entre o fazer histórico do homem e a natureza, é apresentado de modo aparentemente muito nítido, tanto nas ideologias de ocupação do território quanto nas questões formais dos desenhos: "O fazer histórico para o homem, como sabeis, comporta dois aspectos. De um lado, este fazer é dominar a natureza, descobrir seus segredos, fruir de sua generosidade e interpretar suas freqüentes demonstrações de hostilidade. Dominar a natureza foi e é criar uma técnica capaz de obrigá-la a dobrar-se às nossas necessidades e desejos" ${ }^{\prime 20}$. Temos estado este tempo todo diante da reta e da curva, da ordem e do caos, da força moral da virtude e da decadência, da imitação e da transformação da natureza. 
Mas questão da forma na arquitetura continuou sendo tratada, não como um patrimônio coletivo, mas como uma forma única, distinta. Os arquitetos deste século não chegaram a estabelecer uma efetiva e pretendida relação social com a técnica, no sentido de uma função social para a arquitetura. Tampouco elegeram a funcionalidade e a habitabilidade como fator preponderante no projeto. Daí a forma caiu num falso descaso, daí tornar-se também uma coisa em si: "Todo esforço que visa escapar do artifício nele recai com avidez" ${ }^{21}$. A forma ${ }^{22}$, nos seus aspectos plásticos e tecnológicos, passou a ser a representação material de um programa de arquitetura que se pretendia revolucionária, uma "arquitetura como manifesto" ${ }^{23}$.

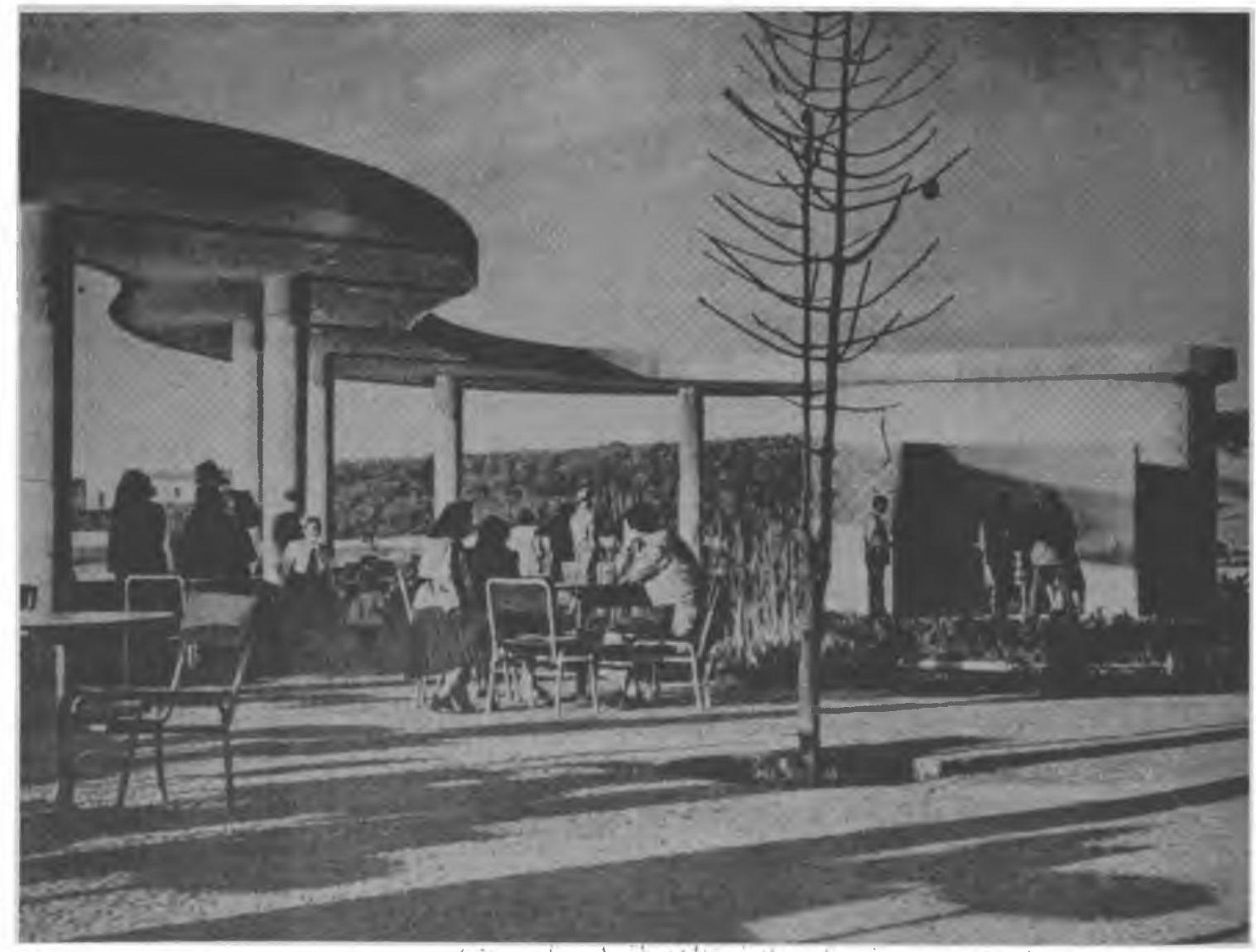

14 - Casa do Baile, Pampulha, Belo Horizonte, Oscar Niemeyer, 1942-1943 (In: FISCHER, Sylvia e ACAYABA, Marlene Milan. Arquitetura moderna brasileira. São Paulo: Ed. Projeto, 1982, p. 15). 


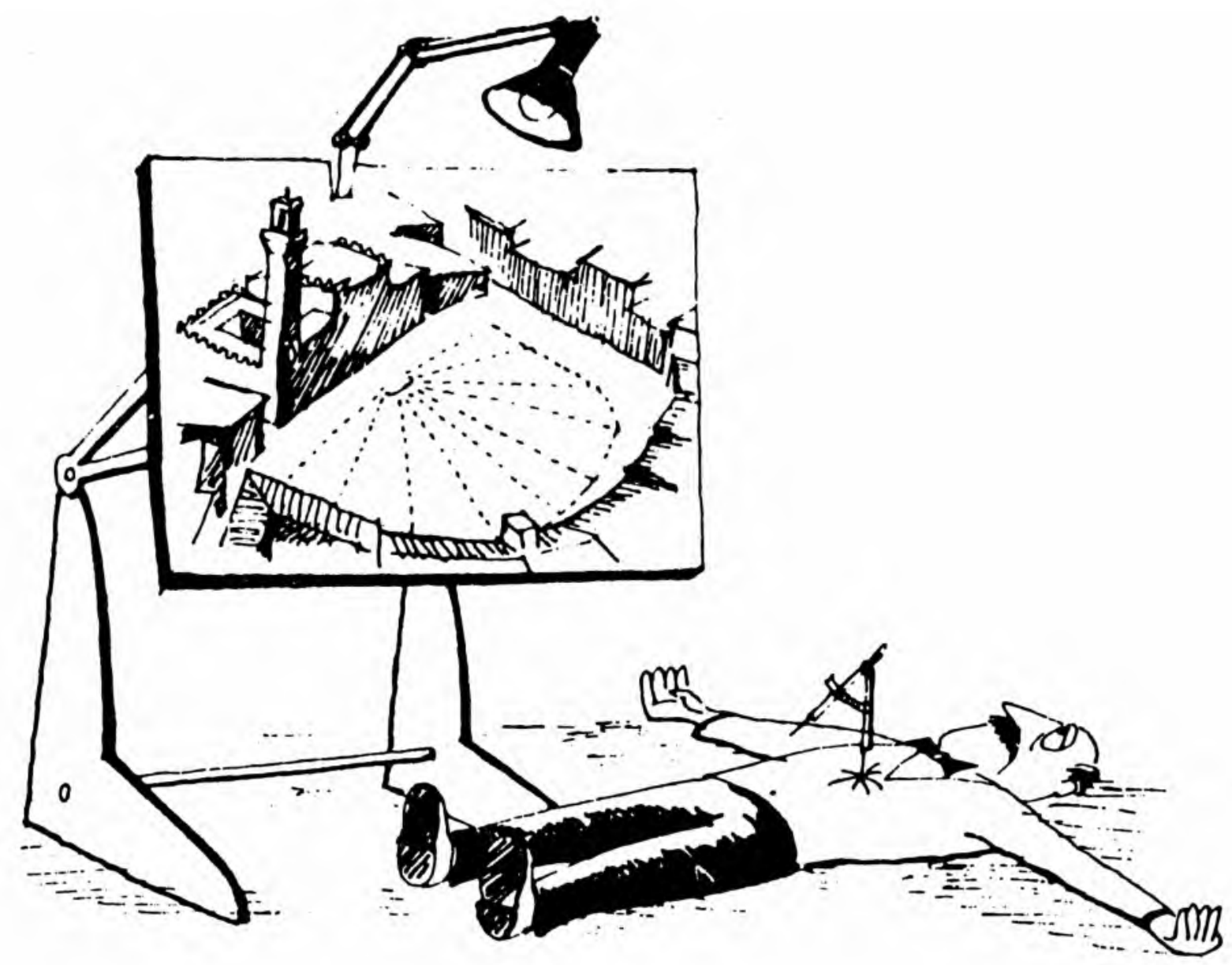

15 - "Com a régua e o esquadro, o estirador e a máquina de desenhar torna-se diffcil e esgotante reproduzir uma situação urbana medieval como a Piazza del Campo, em Siena. Com a ajuda destes instrumentos podem conceber-se unicamente arquiteturas de caixote, facilmente representáveis em perspectivas", Bruno Zevi. (In: ZEVI, Bruno. A linguagem moderna de arquitetura. Lisboa: Martins Fontes, 1984, p. 33).

\section{CONCLUSÃO}

Os aspectos plásticos estão entre aqueles fundamentais da sensibilidade dos paisagistas e arquitetos, como já apuramos, e constituem, por vezes, a única coisa que deles se espera, aí então uma nítida redução de seu campo profissional. Sendo aspectos fundamentais, quais referenciais são identificáveis para sua discussão e elaboração? Já vimos no início deste artigo que os paisagistas tenderam a polarizar a questão do desenho entre $o$ formal e o informal, que remontam a modelos do séculos 17 e 18, e entre estes e o moderno. Em torno daquelas duas possibilidades emblemáticas construíram-se estereótipos de relação 
com a natureza: o geométrico dominador e o naturalista orgânico, minimizando nos debates profissionais as questões mais importantes do tecido urbano e os aspectos culturais da forma.

Os termos formal e informal são, obviamente, inadequados para descrever o conteúdo ideológico e estético que se pretendeu que veiculassem; além de cobrirem apenas uma parte das questões de concepção da forma, são também secundários. É necessário superá-los enquanto estereótipos, fazendo emergir conteúdo cultural presente nas opções de projeto. É necessário resgatar o percurso histórico da profissão, estabelecer seus vínculos culturais com o projeto do ambiente, obter a percepção e contribuição específica que dá ao projeto da paisagem.

Interessa reconstituir, com a história, questões fundadoras para a profissão, recuperando-as como uma discussão válida de um campo cultural que tem impacto em nossas opções de projeto e em nossas representações mentais acerca desse campo. Sua redução produz desenhos estereotipados sinuosos ou axiais que não fazem justiça ao conceito de projeto e de paisagem presentes naqueles protótipos ${ }^{24}$, riquíssimos enquanto opções espaciais e simbólicas, contextualizados em sua época, seu lugar, sua finalidade, no processo que os gera e os faz atravessar o tempo.

O mesmo reducionismo ocorre quando, além de reduzirmos o desenho à reta e à curva, reduzimos o paisagismo a uma oposição entre a natureza e o concreto, isto é, a uma visão agrária oposta ao lote ou ao espaço público, que não discute sua função social, estética, ambiental, na sociedade contemporânea.

Não cremos que o desenho formal signifique uma negação da natureza e que seu outro represente "a respect for nature" como afirmava Eckbo em 50. Nem que um seja despótico e seu outro libertário, um desenho mais duro e amarrado versusum desenho mais solto, como tantas vezes afirmaram professores, arquitetos e paisagistas. Esse tipo de colocações nos afasta das questões mais interessantes. 
É necessário entendê-los - o formal $\mathrm{o} o$ informal (para não reduzir os protótipos a estereótipos) - como SENSIBILIDADES diferentes e discutir o campo SIMBÓLICO e IDEOLÓGICO em que os apropriamos e interpretamos, para entendermos seus conteúdos estéticos. Ao invés de propor um momento em relação ao outro nos termos de um "ápice e um declive", podemos vê-los como "uma arte totalmente diferente" comodescreveu Wolfflin ${ }^{25}$ em 1915, ao estudar arte, arquitetura e escultura do humanismo e do barroco.

Que questões propõe portanto o desenho? Lembrando Artigas ${ }^{26}$, ninguém desenha pelo desenho e há, na razão de ser do desenho, um processo intelectual, uma síntese criativa da "nova técnica" "na criação de novos símbolos", uma bela e rica maneira de propor o programa de sua época, ainda que uma elaboração da cultura, por ser "cultura", exige gestação, tempo, e não apenas um generoso gesto de genialidade. Lembrando também Clifford (1970), para quem "Un jardin es la visión del mundo idealizado por un hombre", a questão fundamental que se coloca é que o projeto é uma possibilidade para atuar no nível criativo dos protótipos e não nos esquemas dos estereótipos.

Esta investigação possivel à atividade projetual é não só a busca da forma, mas do sentido. E aqui abre-se um enorme campo para, como paisagistas; questionarmos as bases de nossa atividade e de nossa sensibilidade hoje. O que implica, segundo pensamos e discutimos noutras oportunidades, analisar a inserção do paisagismo contemporâneo como arte, ciência e natureza em escalas de abrangência que vão do lugar intra-urbano ao ambiente urbano e regional. 


\section{NOTAS}

(*) Este tema foi primeiramente abordado em uma disciplina que ministramos no Curso de Especializaçãoem Paisagismo em 1989 edesenvolvido em nossa dissertação de mestrado.

\section{(1) Citado por Eaton, 1964.}

(2) A questão entre cidade e campoé particularmente viva na Inglaterra e nos EUA: "Aunque la logica interna del desarrollo capitalista norteamericano, lleva aparejada la alta concentración urbana, en coincidencia con la produción industrial y las actividades terciarias, existió tradicionalmente una corriente antiurbana que se remonta a Thomaz Jefferson y persiste a lo largo del siglo XX" com expoentes como Frank Lloyd Wright (Segre, 1985).

(3) Hugh Johnson (citado em Franco, 1989), derivando-o dos campos de irrigaçãoegípcios, vê nesse modelo uma imagem pastoral arquetípica e uma relação pragmática e antropocêntrica com a natureza, expressão do domínio absoluto de uma minoria ociosa.

(4) A polarização formal-informal foi acirrada pelo próprio movimento moderno, em sua oposição aos estatutos das Beaux-Arts. Snow, 1967, vê também um componente estético na rejeição dos padrões da academia: "Mistakenly, (...) revolt (...) focused on the bilateral symmetry of the Beaux Arts which was not really the point, just a symbol of it. It was a convenient symbol, ever present and deeply entrenched in a segment of Western culture. But asymetry or neo-romantic wiggles or any other abstraction would have served just as well because any fixed point of reference is incompatible with a changing view of the landscape and the environment generally"

(5) A tradição dos jardins europeus para Clifford (1970) é a de um "doble carácter ancestral de santuario y bosque consagrado a los heroes".

(6) Assim comentou Roger Fry as diferenças de atitude entre orientais e europeus: "Unosiente que debe ponerse un poco en guardia sobre un pueblo que invento la ceremonia del té, un pueblo que hipnotiza a símismo en una actitude de expectante adoración estetica. Ellos dirían, sin duda, que esta ocupación hipnótica de caminar a lo largo del passeo del jardin en silencio hasta la casa de té, unicamente servía para producir una adequada receptividade para disponerle a uno a una actitud favorable. Pues esto es precisamente: ellos están siempre disponendole a uno a una actitud demasiado favorable, quitandole a uno mediante la hipnósis su sentido comúm crítico. Tienen una manera astuta de hacer que las cosas parezcan preciosas aun antes de que se hayan preparado y ostentarlas con exquisito gusto" (citado por Clifford, 1970). 
(7) "We can sum up the formal tradition as a tradition of unified architectural conceptions in which indoors and outdoors structural and natural elements, were integrated to produce complete site-space organizations: it is a tradition of planned organization of open space in most simple, direct, logical and rational manner. It is a clear and positive expression of man's separation from and or authority over nature, of the authority of some men over many other men, and of the culture, wealth, and power of those dominant few. It was produce in a complete final form, before the dicovery of the industrial techniques for mass production of goods and wealth, by cultures basically autocratic in social structure" (Eckbo, 1950).

(8)" A linguagem paisagística desses parques, herança direta dojardim ing/ês do século 18, contrapunha-se à tradição do jardim francês. Era a linguagem que convinha ao novo elemento do desenho urbano. Não somente foi utilizado na Inglaterra, mas, transpondo o canal e o oceano, acaba sendo a expressão dos parques franceses e americanos. Acompanhando as novas idéias de volta à natureza e, de certa forma, influenciados pela cultura oriental os paisagistas ingleses introduzem o modelo paisagístico de linhas curvas, de modelado do terreno em colinas macias, rios e lagos imitando as formas da natureza, em contraposição aos tanques e canais geométricos do passado, e o uso da vegetação numa linguagem informal de extensos gramados e grupos de árvores, de forma a sugerirem paisagens naturais" (Kliass, 1989).

(9) No Plano Avenidas, Prestes Maia propunha a substituição do "desenho antiquado" da praça da República por um novo, de caráter formal, inspirado no Capitólio de Washington: "Com a expansão do centro o logradouro começa a destoar da sua moldura de casas comerciais e de tráfego intenso que o circunda. Por outro lado os novos parques, que se projetam, substituirão com vantagem o seu paisagismo demasiado artificial (...) No fundo, um grande edifício destinado a substituirfuturamente a Escola Normal dominará a praça com a sua massa e fechará com sua cúpula a perspectiva da Av. Principal. Scenário comparável à praça do Congresso buenayrense e talves mais bem proporcionado" (Maia, 1930).

(10) "These two contrasting components of the world landscape tradition western geometry and eastern irregularity, authority of man and respect for nature, the straight line and the free curve - are still in the twentieth century the cornerstones of the official theory of formal and informal landscape design as taught in American professional schools" Eckbo, 1950.

(11) Essa polarização comparece nos escritos de Sitte (1980) e Corbusier (1962), Garnier (1932) e Unwin (1984), Cullen (1984) e Lynch (1982). Comparece nas nossas capitais planejadas, como Belo Horizonte, Goiânia e Brasília.

(12) Frederico Liberalli, citado por Segawa, 1988. 
(13) "...o seu Código de Obras Arthur Saboya, no art. 146 determina: Oestilo arquitetônico e decorativo é completamente livre, enquanto não se oponha ao decoro e à regra de construir. A Diretoria de Obras poderá recusar os projetos de fachadas que acusam um flagrante desacordo com os preceitos básicos da arquitetura" e: "Imagine-se o que será essa cidade-jardim se continuarem a aparecer as casas tumulares de cimento armado. Será inevitável a desvalorização desses terrenos, que mais parecerão um prolongamento do cemitério do Araçá" (Christiano das Neves, citado por Ferraz, 1965).

(14) Le Corbusier, 1961.

(15) "El hombre moderno que se tatua es un delinquente o un degeneradd", citado em Conrads, 1973.

(16) Giedion, 1958; Pevsner, 1981.

(17) Le Corbusier, 1962.

(18) Citado por Santos, 1981.

(19) Le Corbusier, 1962.

(20) Artigas, 1986.

(21) Rosset, 1989.

(22) A preocupação formal jamais deixou de ser uma nota distintiva da arquitetura, mesmo que a palavra "estilo", usada com tanta naturalidade antes, passasse a ter uma conotação negativa no movimento moderno, representando o descuido das questões funcionais, estruturais e de organização espacial do projeto, alguma coisa como "cosmético" de fachadas.

(23) Stroeter, 1986.

(24) Se pensarmos em Versalhes ou Storhead, seremos forçados a admitirque esses parques representaram uma visão do mundo e da sociedade, e que organizaram o território, ainda num contexto em que o conflito campocidade não se colocava com toda a sua força. Ambos são protótipos, são intensamente criativos e igualmente artefatos, produtos estéticos que se valem da natureza de modos diversos subordinada à sensibilidade do desenho e do trabalho humano para criar ambientes para uso e fruição.

(25) Wolfflin 1984.

(26) "Como se viu, ninguém desenha pelo desenho. Para construir igrejas há que tê-las na mente, em projeto. Parodiando Bluteau, agrada-me interpelarlos, particularmente os mais jovens, os que ingressam hoje em nossa Escola: que catedrais tendes no pensamento? Aqui aprendereis a construí-las duas vezes: aprendereis da nova técnica e ajudareis na criação de novos símbolos. Uma síntese que só ela é criação" (Artigas, 1986). 


\section{BIBLIOGRAFIA}

ARTIGAS, V. Caminhos da arquitetura. São Paulo: Pini, 1986.

CHURCH, T. D. Gardens are for people. How to plan for outdoor living. New York: Reinhold P.C., 1955.

CLIFFORD, D. Los jardines. Historia, trazado, arte ... Madrid: Instituto de Estudios de Administración Local, 1970.

CONRADS, U. Programas y manifiestos de la arquitectura de siglo XX. Barcelona: Lumen, 1973.

CULLEN, G. Paisagem urbana. São Paulo: Martins Fontes, 1984.

EATON, Leonard K. Landscape artist in America. The life and work of Jens Jensen. Chicago \& London: The University of Chicago Press, 1964.

ECKBO, G. Landscape for living. USA: F.W. Dodge Corporation, 1950.

FERRAZ, G. Warchavchik e a introdução da nova arquitetura no Brasil: 1925 e 1940. São Paulo: MASP, 1965.

FRANCO, M. A. R. Espaço livre e arquitetura. São Paulo, 1989. Dissertação (Mestrado). Faculdade de Arquitetura e Urbanismo Universidade de São Paulo.

GARNIER, T. Une cité industrielle, étude pour la construction dés villes. Paris, 1932.

GIEDION, S. Espacio, tiempo yarquitectura. 2. ed. Barcelona: Editorial Científico-Médico, 1958.

HUBBARD, H. V., KIMBALL, T. An introduction to the study of landscape design (1917). New York: The MacMillan Company, 1927.

JELLICOE, G. and S. The landscape of man shaping the environment from history to present day. London: Thames and Hudson, revised edition 1987. 
JOHNSON, J.; FRANKEL, F. Modern landscape architecture. Redefining the garden. New York: Abbeville Press, 1991.

KLIASS, R. G. A evolução dos parques urbanos na cidade de São Paulo. SãoPaulo, 1989. Dissertação(Mestrado). Faculdade de Arquitetura e Urbanismo - Universidade de São Paulo.

LE CORBUSIER. La ciudad del futuro. Buenos Aires: Ediciones Infinito, 1962.

Por uma arquitetura. 3. ed. São Paulo: Perspectiva, 1981.

LYNCH, K. A imagem da cidade. São Paulo: Martins Fontes, 1982.

MAIA, F. P. Estudo de um planode avenidas para a cidade de São Paulo. São Paulo: Melhoramentos, 1930.

PEVSNER, N. Origens da arquitetura moderna e do design. São Paulo: Martins Fontes, 1981.

ROSSET, C. A anti-natureza. Elementos para uma filosofia trágica. Rio de Janeiro: Espaço e tempo, 1989.

SANDEVILLEJR, E. A herança da paisagem. SãoPaulo, 1993. Dissertação (Mestrado). Faculdade de Arquitetura e Urbanismo-Universidade de São Paulo.

SANTOS, P. F. Quatro séculos de arquitetura. Rio de Janeiro: IAB, 1981.

SEGAWA, H. Construção de ordens. Um aspecto de arquitetura no Brasil 1808-1903. São Paulo, 1988. Dissertação (Mestrado). Faculdade de Arquitetura e Urbanismo - Universidade de São Paulo.

SEGRE, R. História de la arquitectura y del urbanismo. Paises desarrollados, siglos XIX y XX. Madrid: Instituto de Estudios de Administración Local, 1985.

SITTE, C. Construccion de ciudades según principios artisticos. Barcelona: Gustavo Gili, 1980. 
SNOW, M. Modern gardens designed by James Rose. New York: Reinhold, 1967

STROETER, J.R. Arquitetura \& teorias. São Paulo: Nobel, 1986.

UNWIN, R. La practica del urbanismo. Uma Introduccion al arte de proyectar ciudades y barrios. Barcelona: Gustavo Gili, 1984.

WOLFFLIN, H. Conceitos fundamentais da história da arte. São Paulo: Martins Fontes, 1984. 